\title{
Babesia microti Infection Changes Host Spleen Architecture and Is Cleared by a Th1 Immune Response
}

\author{
Vitomir Djokic ${ }^{\dagger}$, Lavoisier Akoolo' ${ }^{\dagger}$ and Nikhat Parveen*
}

Department of Microbiology, Biochemistry and Molecular Genetics, Rutgers New Jersey Medical School, Newark, NJ, United States

Babesia microti is a malaria-like parasite, which infects 2000 people annually, such that babesiosis is now a notifiable disease in the United States. Immunocompetent individuals often remain asymptomatic and are tested only after they feel ill. Susceptible $\mathrm{C} 3 \mathrm{H} / \mathrm{HeJ}$ mice show several human-like disease manifestations and are ideal to study pathogenesis of Babesia species. In this study, we examined parasitemia of B. microti at different time points and assessed its impact on hemoglobin levels in blood, on spleen pathology and overall immune response in $\mathrm{C} 3 \mathrm{H} / \mathrm{HeJ}$ mice. Peak parasitemia of $42.5 \%$

OPEN ACCESS

Edited by:

Wanderley De Souza Universidade Federal do Rio de Janeiro, Brazil

Reviewed by: Mario M. D'Elios, University of Florence, Italy

Marcello André Barcinski, National Institute of Metrology (INMETRO), Brazil

*Correspondence: Nikhat Parveen parveeni@njms.rutgers.edu

tThese authors have contributed equally to this work.

Specialty section: This article was submitted to Microbial Immunology, a section of the journal Frontiers in Microbiology

Received: 07 September 2017 Accepted: 12 January 2018 Published: 31 January 2018

Citation:

Djokic V, Akoolo L and Parveen N (2018) Babesia microti Infection Changes Host Spleen Architecture and Is Cleared by a Th1 Immune Response. Front. Microbiol. 9:85. doi: 10.3389/fmicb.2018.00085 was immediately followed by diminished hemoglobin level. Parasitemia at 21 days of infection was barely detectable by microscopy presented $5.7 \times 10^{8}$ to $5.9 \times 10^{9}$ B. microti DNA copies confirming the sensitivity of our qPCR. We hypothesize that qPCR detects DNA released from recently lysed parasites or from extracellular $B$. microti in blood, which are not easily detected in blood smears and might result in underdiagnosis of babesiosis in patients. Splenectomized patients have been reported to show increased babesiosis severity and result in high morbidity and mortality. These results emphasize the importance of splenic immunity in resolution of $B$. microti infection. Splenomegaly in infected mice associated with destruction of marginal zone with lysed erythrocytes and released $B$. microti life forms in our experiments support this premise. At conclusion of the experiment at 21 days post-infection, significant splenic $B$ and $T$ cells depletion and increase in macrophages levels were observed in B. microti infected mice suggesting a role of macrophage in disease resolution. Infected mice also showed significantly higher plasmatic concentration of CD4 Th1 cells secreted cytokines such as IL-2 and IFN- $\gamma$ while cytokines such as IL-4, IL-5, and IL-13 secreted by Th2 cells increase was not always significant. Thus, Th1 cells-mediated immunity appears to be important in clearance of this intracellular pathogen. Significant increase in IL-6 that promotes differentiation of Th17 cells was observed but it resulted in only moderate change in IL-17A, IL-17F, IL-21, and IL-22, all secreted by Th17 cells. A similar immune response to Trypanosoma infection has been reported to influence the clearance of this protozoan, and co-infecting pathogen(s).

Keywords: Babesia microti, protozoan pathogenesis, babesiosis, tick-borne infection, immunosuppression, blood-borne pathogen

Abbreviations: FISH, fluorescence in situ hybridization; IFA, indirect immunofluorescence assay; qPCR, real-time quantitative polymerase chain reaction; TTB, transfusion transmitted babesiosis. 


\section{INTRODUCTION}

Tick-borne diseases have been increasing steadily in the last two decades in North America and Europe that include bacterial, viral and parasitic pathogens. Transmission of multiple pathogens by a single tick bite has been reported to occur (Dunn et al., 2014; Rizzoli et al., 2014; Moutailler et al., 2016). Babesia species are tick-transmitted parasites with the most cases of babesiosis attributed to Babesia microti in the United States, with some patients show infection with $B$. duncani in Western states, while $B$. divergens is primarily responsible for babesiosis in Europe (Centers for Disease Control and Prevention, 2012). Approximately 2000 cases of babesiosis occur in the United States every year, which resulted in its declaration as a notifiable disease by $\mathrm{CDC}$ in 2011. B. microti infection affects the Northeastern United States; Connecticut, Massachusetts, New Jersey, New York, and Rhode Island along with the Midwestern states of Wisconsin and Minnesota (Knapp and Rice, 2015). Together they represented $94 \%$ of babesiosis cases in the United States in 2014.

Babesia species are intracellular parasites of red blood cells (RBCs), where they multiply until erythrocytes burst. Clinical disease ranges from asymptomatic or mild flu-like symptoms in immunocompetent people, including fever and myalgia, to acute or sometimes fatal disease in immunocompromised or splenectomized individuals (Genda et al., 2016). Patients are often tested for babesiosis only after observation of hemolytic anemia. Babesia species can also transmit through transplacental route and can cause jaundice, anemia and neutropenia in children (Joseph et al., 2011, 2012; Luckett et al., 2014). Immunocompetent individuals can establish Babesia carriage state without any clinical manifestations for long periods of time. Due to survival of these parasites during cold storage, infected donated whole blood and blood products can cause blood transfusion transmitted babesiosis (TTB) that have severe consequences in the immunocompromised patients (Herman et al., 2010; Herwaldt et al., 2011; Sinski et al., 2011; Cushing and Shaz, 2012; Cursino-Santos et al., 2014; Fang and McCullough, 2016). Babesiosis is the most prevalent transfusion transmitted disease in the United States such that FDA has recently recommended that blood donors should be screened for Babesia infection (Lobo et al., 2013; United States Food and Drug Administration, 2014).

Current confirmatory test for babesiosis is microscopic examination of Giemsa-stained blood smears. However, this method is time consuming and requires a specific expertise for correct diagnosis because pleomorphic, non-synchronous trophozoites and ring forms can make Babesia identification difficult. This method is also very labor intensive. Therefore, it cannot be used for large scale testing of donated blood samples. Some diagnostic laboratories employ FISH for diagnosis of babesiosis that also requires microscopic examination. Serologic tests are more sensitive and efficient; however, these tests cannot detect acute disease before the adaptive immune response is established and are also unable to distinguish active disease from the past infections or reinfections, thus, creating a major diagnostic problem particularly in the endemic regions
(Magnarelli et al., 1998; Foppa et al., 2002; Hunfeld et al., 2002; Yoshinari et al., 2003; Fox et al., 2006; Vannier et al., 2008; Lempereur et al., 2015; Mayne, 2015; Wormser et al., 2015). Nucleic Acid Tests have been used for examination of both humans and ticks and have more promise for diagnosis of babesiosis including blood donors (Bose et al., 1995; Krause et al., 1996a; Cushing and Shaz, 2012; Michelet et al., 2014; Jahfari et al., 2016). We found that our, molecular beacon probes based real-time quantitative Polymerase Chain Reaction (qPCR) test, identifies patient samples with babesiosis with greater sensitivity, in a tick-borne diseases endemic state, New Jersey.

White footed mouse is natural reservoir of $B$. microti in the United States. Susceptible $\mathrm{C} 3 \mathrm{H}$ mice show several manifestations like humans and offer ideal animal model system to investigate pathogenesis of this protozoan parasite (Ruebush and Hanson, 1979). Observation of pronounced splenomegaly in $B$. microti infected $\mathrm{C} 3 \mathrm{H} / \mathrm{HeN}$ mice as well as higher parasitemia levels and delayed clearance of B. microti from blood stream of splenectomized mice indicate importance of spleen immunity in resolution of babesiosis even in mice (Coleman et al., 2005). B. microti parasitemia also reduced in Severe Combined Immunodeficient (SCID) mice by adoptive transfer of splenocytes from naïve immunocompetent mice, further emphasizing the role of adaptive immune response facilitated by splenic cells (Vannier et al., 2004). However, a systematic study to assess the consequence of $B$. microti infection on mice together with both plasmatic and splenic immunity has not been carried out until now. Therefore, B. microti pathogenesis and immunological response to this intraerythrocytic pathogen remain poorly understood. Involvement of innate immunity determined by macrophage during B. microti infection was suggested to play the primary role in babesiosis resistance in mice (Aguilar-Delfin et al., 2001; Terkawi et al., 2015). Adoptive transfer of primed $\mathrm{T}$ cells was reported to control mice reinfection by $B$. microt $i$ likely due to also simulating primed $\mathrm{B}$ cell response (Meeusen et al., 1985). Furthermore, CD4 and not CD8 cells were shown to participate in elimination of $B$. microti in mouse infection model (Hanafusa et al., 1998; Igarashi et al., 1999; Hemmer et al., 2000a). Interestingly, human Babesia WA1 parasites infection in mice resulted in upregulation of both TNF $\alpha$ and IFN $\gamma$ resulting in severe pathogenesis and fatal disease (Hemmer et al., 2000b). Surprisingly, anti-IFN $\gamma$ monoclonal antibodies partially reduced protection of mice immune against $B$. microti and IFN $\gamma$-deficient mice did not offer any protection against $B$. microti infection (Igarashi et al., 1999).

We followed the multiplication cycle of B. microti in blood of $\mathrm{C} 3 \mathrm{H} / \mathrm{HeJ}$ mice and assessed the impact of parasitemia increase on hemoglobin levels in blood, on spleen pathology and on overall splenic and plasmatic immune response. Our studies demonstrate that innate immune response particularly due to macrophage participation and adaptive immune response triggered by stimulation of CD4 cells play critical roles in elimination of parasitized erythrocytes during infection of mice with B. microti. Furthermore, we also describe potential reason for under detection of $B$. microti during human infection. 


\section{MATERIALS AND METHODS}

\section{Human Samples}

Blood samples from 133 patients collected in 2015 from three different counties in New Jersey as described previously were used in this study (Akoolo et al., 2017). Patients presenting different clinical symptoms were recommended for testing for tick borne diseases for initial evaluation, or follow-up care. IGeneX tested air-dried blood smears for babesiosis by FISH using $18 \mathrm{~S}$ rDNA/rRNA as target. Stony Brook Laboratory for Lyme disease performed serological testing by Indirect IFA. Blood testing for babesiosis was conducted by microscopic examination of Giemsa-stained smears. Remnant, coded sample aliquots (collected for their own testing) were provided for another study to the corresponding author. Results of their tests were provided in unidentifiable/anonymized manner under corresponding author's approved, exempt-Institutional Review Board (e-IRB) protocol, Pro2013002634, approved by Institutional Review Board of Rutgers New Jersey Medical School.

\section{B. microti Infection Cycle in $\mathrm{C} 3 \mathrm{H} / \mathrm{HeJ}$ Mice}

The Newark Institutional Animal Care and Use Committee (IACUC) designated members reviewed and approved the protocol number D-14011-A1 under which this study was conducted at Rutgers University New Jersey Medical School following guidelines of the Animal Welfare Act, The Institute of Laboratory Animal Resources Guide for the Care and Use of Laboratory Animals, and Public Health Service Policy. B. microti (ATCC30221) was first propagated in SCID mice to obtain inoculum for subsequent experiments because these parasites adapted to a particular host allow manifestation of full spectrum of pathogenesis of $B$. microti (Gumber et al., 2016). Ten 4 weeks old $\mathrm{C} 3 \mathrm{H} / \mathrm{HeJ}$ mice were infected at a dose of $10^{4}$ parasitized RBCs/mouse. To determine parasitemia, 5-10 $\mu$ l blood was collected from each infected mouse by tail bleed to prepare blood smears that were Giemsa-stained according to CLSI guidelines (Garcia et al., 2000). On the day of infection experiment in immunocompetent $\mathrm{C} 3 \mathrm{H} / \mathrm{HeJ}$ mice, blood was collected from SCID animals and inoculum dose determined. Briefly, total erythrocytes per milliliter of blood were determined using a hemocytometer and parasitized RBCs counted in a total of 2050 fields at high magnification. Numbers of infected RBCs were determined by multiplying percent parasitemia with the total count of RBCs $/ \mathrm{ml}$ of blood. The number of parasitized RBCs was then adjusted to $10^{5} / \mathrm{ml}$ in PBS and $100 \mu \mathrm{l}$ suspension injected in each mouse intraperitoneally such that infection dose of $10^{4}$ infected erythrocytes per animal was used to infect 4 weeks old $\mathrm{C} 3 \mathrm{H} / \mathrm{HeJ}$ mice. Five uninfected mice were included as controls for all analyses.

\section{Monitoring of Parasitemia in Blood of Infected Mice}

Blood smears from the infected mice were prepared, and Giemsa stained. Blood smears were then examined to determine parasitemia and thus, progression of $B$. microti infection up to 21 days of infection. Blood hemoglobin levels were determined using a commercial kit (Hemocue ${ }^{\circledR}$ Hb 201+ analyzer, Sweden) according to the manufacturer's instructions. Mice were euthanized at 21 days post infection and evaluated further for disease pathology. Before euthanasia, heparinized blood was collected from each mouse by cardiac puncture and then mice were euthanized. Plasma was recovered after centrifugation for cytokine profile determination.

\section{IFA to Detect B. microti in Blood and Spleen}

For paraffin embedded spleen sections, slides were immersed in xylene two times for $10 \mathrm{~min}$ interval to remove paraffin and was followed by immersion in $100 \%$ ethanol twice and then immersion in 95,70 , and $50 \%$ ethanol for 5 min each. A final rinse with water was followed by rehydration in PBS. Slide edges were marked with hydrophobic marker and then IFA was conducted as described previously using pooled patient sera from four individuals that tested positive in our previous studies (Akoolo et al., 2017). Staining with 2-(4-amidinophenyl)-1H-indole-6carboxamidine (DAPI) was included to stain nucleus with the anti-human secondary antibody conjugated to Alexa fluor 488 (Molecular Probes).

\section{Quantification of B. microti in Blood by qPCR}

DNA was isolated from mice blood using QIAamp Blood midi kit (Qiagen). Duplex qPCR was conducted using different dilutions of genomic using the primers and molecular beacon probe for gene encoding Thiamine pyrophosphokinase (B. microti TPK) as we described previously (Chan et al., 2013; Akoolo et al., 2017). Amplification was performed in $25 \mu \mathrm{l}$ reaction mixtures. Based upon the genome size $(6.5 \mathrm{Mb})$, of $B$. microti, $8 \mathrm{ng}$ of DNA was calculated to contain $10^{6}$ copies of B. microti TPK gene. A standard curve was prepared using 10-fold dilutions of B. microti genomic DNA. Leukocytes from mouse blood were used to amplify Nidogen gene as an internal control. Inclusion of this control ensured that the quality of DNA was suitable for PCR (Chan et al., 2013).

\section{Isolation of and Characterization of Splenocytes by Flow Cytometry}

Aseptically harvested spleens from infected and uninfected mice were imaged, weighed and single cell suspension of the splenocytes prepared. Briefly, spleen was sliced into small pieces and strained through a $70 \mu \mathrm{m}$ nylon sterile cell strainer into $50 \mathrm{ml}$ conical tube. After washing cells with Phosphate buffered saline by centrifugation at 1,500 rpm, RBCs were lysed using Ammonium-Chloride-Potassium lysis buffer (Thermo Fisher). The splenocytes were then resuspended in FACS buffer at $10^{6} / \mathrm{ml}$ concentration and stained by labeling with respective marker antibodies tagged with different fluorophores. For staining, the cells were incubated for $30 \mathrm{~min}$ in the dark at $4^{\circ} \mathrm{C}$ using the fluorophores tagged antibodies; B cells with Brilliant violet 421 anti-mouse CD19 antibody (Biolegend), NK cells with APC-Cy7 
anti-mouse NK1.1 antibody (Bilegend), CD3 with PE-Cy7 antimouse CD3 antibodies (Biolegend), and macrophages with antimouse F4/80 Brilliant violet 605 antibody. The cells were washed with PBS containing 2\% FBS by centrifugation, and resuspended in Fluorescence Activated Cell Sorting (FACS) buffer. Cells were sorted using a flow cytometer BD LSRFortessa ${ }^{\mathrm{TM}}$ X-20 (BD Biosciences) driven by software FACS DiVa (BD Biosciences). Analysis of the acquired data was performed using software, FlowJo, Version 10.3.

\section{Determination of Plasmatic Cytokines Changes in the Infected Mice}

Heparinized blood samples were centrifuged and plasma was collected. Major cytokines were detected and quantified using commercial bead-based immunoassay kit LEGENDplex ${ }^{\mathrm{TM}}$, mouse multiplex cytokine panel (Biolegend) according to manufacturer's instructions with cytokines IFN- $\gamma$, TNF- $\alpha$, IL-2, IL-4, IL-5, IL-6, IL-10, IL-13, IL-17A, IL-17F, IL-21 and IL-22 analyzed. Briefly, all plasma samples were diluted in 1:1 in assay buffer and all analyses were performed in duplicates for each sample. Samples were treated according to Biolegned's standard protocol, washed using the filter plates, and then examined using the BD LSRFortessa ${ }^{\mathrm{TM}}$ X-20 (BD Biosciences) driven by software FACS DiVa (BD Biosciences). Calculations were performed using Legendplex 7.1 application (Vigene Tech Inc.).

\section{Statistical Analysis}

All data collected was analyzed by GraphPad Prism 7.0a (GraphPad Software). Results are presented as mean \pm standard deviation (S.D.). Comparisons were made between groups using unpaired student two-tailed $t$-tests for unequal variance to determine statistical significant difference between paired groups. Thus, values below 0.05 were considered significant for a paired group comparison at $95 \%$ confidence interval.

\section{RESULTS}

\section{B. microti Infection Is Detected More Efficiently by qPCR Than IFA, FISH, or Blood Smear Microscopy}

All patient samples were tested three times and are shown as positive $(+)$ or negative $(-)$ for each test. Thus, $(+++)$ depict that assay was positive all three times while $(+)$ indicates one positive out of three repeats, likely due to low parasitemia. Out of 133 human tested samples, qPCR detected 71 positive and 62 negatives. Seven samples were positive by both qPCR and IFA, 16 by qPCR and FISH, and 15 by qPCR and microscopic examination of Giemsa-stained blood smears (Figure 1). We detected 21 qPCR positive samples that were negative by IFA, five that were FISH negative, and four in which parasites-infected erythrocytes were not detected by microscopy (Figure 1). Almost all qPCR negative samples (60/62) were negative in other diagnostic tests. Only two samples that were positive by IFA and FISH produced negative qPCR results (Figure 1). Thus,

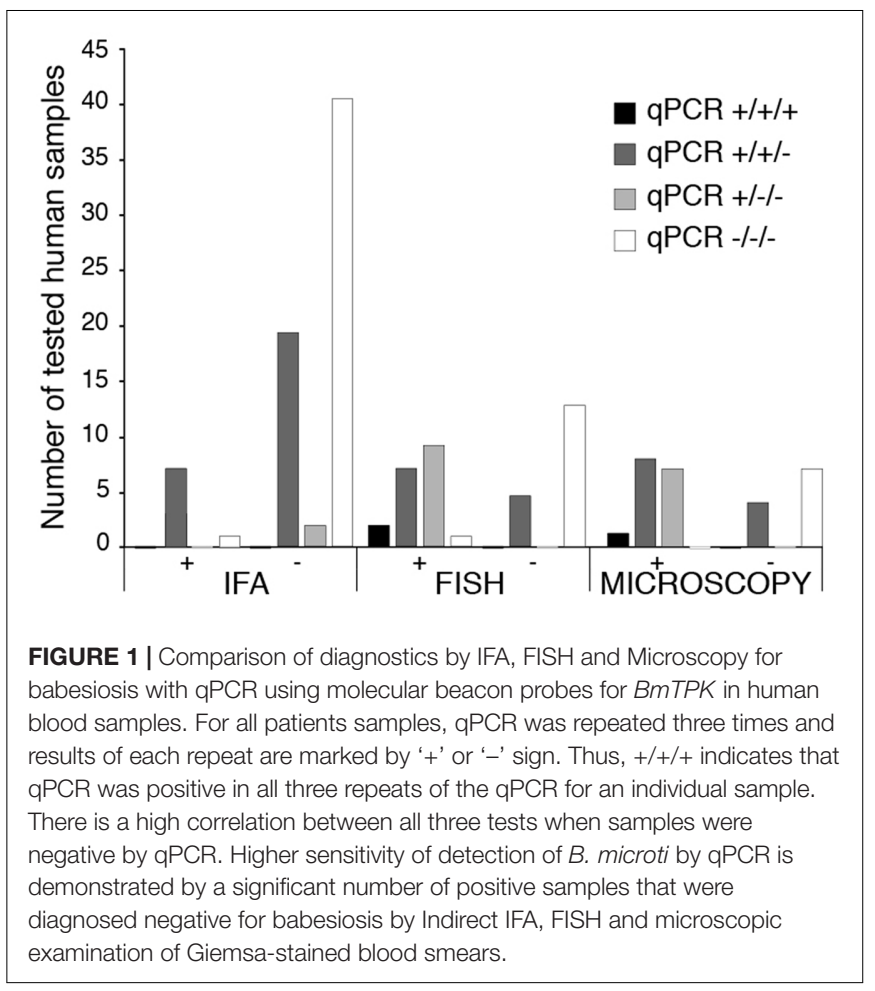

our qPCR could detect $B$. microti presence in blood in a more sensitive manner than other currently used tests.

\section{Parasitemia Pattern in Mice Detected by Microscopy}

We inoculated ten $\mathrm{C} 3 \mathrm{H} / \mathrm{HeJ}$ mice with $B$. microti to study its pathogenesis. Seven days after infection, $0.1 \%$ parasitemia was obtained that steadily increased and culminated to its peak level of average $42.5 \%$ on 13th day of infection (Figure 2A) and then started declining. Increased $B$. microti parasitemia was followed by depletion of RBCs and decreased hemoglobin. One day after observed peak parasitemia, i.e., on day 14 of infection, hemoglobin levels reached to the minimal levels of $3.3 \mathrm{~g} / \mathrm{dl}$. Hemolytic anemia is also a hallmark of symptomatic babesiosis in humans. With subsequent decline in parasitemia, hemoglobin levels started returning to normal values with the value of $9.8 \mathrm{~g} / \mathrm{dl}$ detected on $21 \mathrm{st}$ day post infection (Figure 2A). At this time point, parasitemia was barely detectable $(<0.03 \%)$ by microscopic examination of Giemsa-stained blood smears. We then performed qPCR to assess the presence of the parasitic DNA in blood at this stage of infection because our qPCR was found to be more sensitive in detection of $B$. microti presence in the human blood (Figure 1). Our results with mouse samples confirmed the sensitivity of the qPCR test because surprisingly, high parasitic DNA copy numbers of $5.7 \times 10^{8}$ to $5.9 \times 10^{9}$ were detected in different infected mice at this stage (Figure 2B). To identify cause of this discrepancy between two tests, and determine whether persistence of $B$. microti DNA in blood was responsible for our qPCR results, we further examined blood smears more carefully and identified several B. microti 


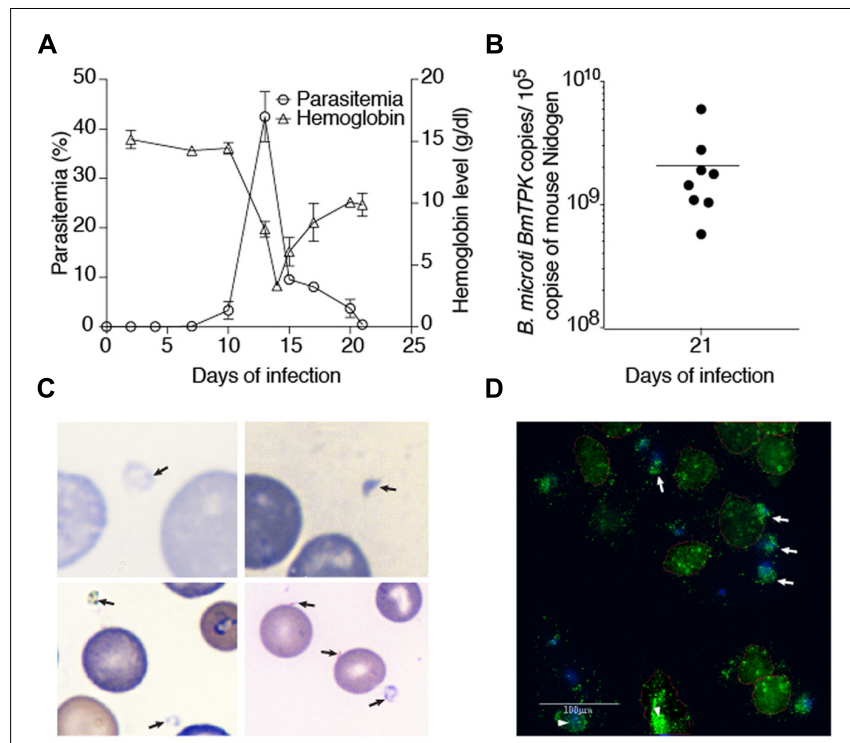

FIGURE 2 | Course of $B$. microti infection and detection of parasites in blood of susceptible $\mathrm{C} 3 \mathrm{H} / \mathrm{HeJ}$ mice. (A) Increase in parasitemia resulted in a dramatic drop in hemoglobin levels reaching the lowest levels 1 day after peak B. microti parasitemia was obtained. Recovery of hemoglobin was rapid after decline in parasitemia. Parasitized erythrocytes were barely detectable by microscopy on 21st day of infection. (B) High copy numbers of B. microti DNA were present in blood of the infected animals at this stage of infection. (C) Several extracellular, released parasites can be observed in Giemsa stained blood smear of infected mice supporting our qPCR results.

(D) The presence of external, released green fluorescent B. microti (marked by arrows) as well as intracellular parasites (marked by arrowheads) were observed by IFA of the blood smears confirming Giemsa stained blood smears results shown in $(\mathbf{C})$

structures outside the erythrocytes (Figures 2C,D). Detection of these parasites explains release of parasites from lysed RBCs and corroborates our qPCR results. It is possible that these released parasites failed to infect RBCs due to significantly reduced levels of mature erythrocytes in blood (Borggraefe et al., 2006; Skariah et al., 2017). The lack of detection of B. microti DNA in the control mice was as expected (data not shown).

\section{Effect of B. microti Infection on Spleen of Mice}

Spleen is considered to play an important role during babesiosis in patients such that splenectomized patients show more severe life-threatening disease. Systematic analysis of contribution of spleen in babesiosis resolution in humans is not possible. Therefore, we decided to study the impact of $B$. microti infection on spleen of infected mice. Spleen sizes of B. microti infected mice consistently increased, i.e., significantly higher than that of the spleen sizes of the naïve mice, as described previously (Coleman et al., 2005). Comparative sizes of infected and naïve mice, five mice each, are shown (Figure 3A). Weights of spleen correlated with their increased size in the infected mice (average weight $0.743 \mathrm{~g}$ ) as compared to naïve animals average weight $0.08 \mathrm{~g}$ ) and difference was statistically significant $(p<0.0001,95 \% \mathrm{CI})$. Histopathological examination of spleen sections after Hematoxylin-Eosin staining showed depletion of marginal zone in $B$. microti infected animals. In addition, enlarged red and white pulps were observed in the spleens of the infected mice such that these two zones were found interwoven throughout the organ (Figure 3B). A careful examination of spleen sections under high magnification also showed the presence of lysed RBCs as well as extracellular B. microti life forms (Figure 3B). The presence of the released, extracellular parasites in spleen was further confirmed by IFA (Figure 3C). Spleen and liver are the major organs of reticuloendothelial system. This system plays a critical role in degradation of defective erythrocytes and cleaning the blood impurities. In our experiments, mouse spleen appears to play a role in clearance of parasitized RBCs. It is possible that another organ of this system, liver, could also play a role in removal of $B$. microti infected RBCs.

\section{Effect of B. microti Infection on Splenic Immune Cells}

We further examined whether there are changes in splenocytes involved in immunity to allow clearance of infected RBCs. Surprisingly, B. microti infected mice on day 21 post infection showed difference in numbers of splenic B, T cells, and macrophages in comparison with naïve animals. Total cell count from each mouse for FACS analysis was adjusted to $100,000 /$ per mouse. Significant depletion of both CD19+ $B$ cells from an average of total 39,655 (39.6\%) in naïve to $16,119(16.3 \%)$ in B. microti infected mice, and from total average $18,423(18.42 \%) \mathrm{CD} 3+\mathrm{T}$ cells in control group to $10.1 \%$ in $B$. microti infected mice were observed consistently. These observations indicate that $B$. microti infection causes significant subversion of adaptive immune response determine by spleen. Interestingly, macrophages (F4/80) levels were higher with total average of 6,641 (6.6\%) macrophage in mice infected with B. microti as compared to an average of 1,892 (1.9\%) in control animals. Splenic NK1.1 cells total count and percentage remained unaffected after $B$. microti infection 20,781 versus 20,615 (20.8\% versus $20.6 \%$ ), respectively. These results indicate a major role of innate immune response in clearance of parasites. Increase in splenic macrophage suggests their contribution in clearance of parasitized erythrocytes that reach spleen as an organ in reticuloendothelial system. Although no changes in splenic NK1.1 cell percentage were observed, their role in resolution of parasitemia cannot be ruled out. Enlargement and dark color of spleen of $B$. microti infected mice could be due to increased hematopoietic support and increased macrophages activity resulting in erythrophagocytosis.

\section{Detection of Mouse Pro-inflammatory Cytokines in Plasma}

The cytokine superfamily of proteins is involved in the signaling and communications between cells. They are fingerprints of the immune response generated in response to infection, injury or even cancer. Plasmatic cytokine profile is more important for clearance of blood borne pathogens. Therefore, we decided to 


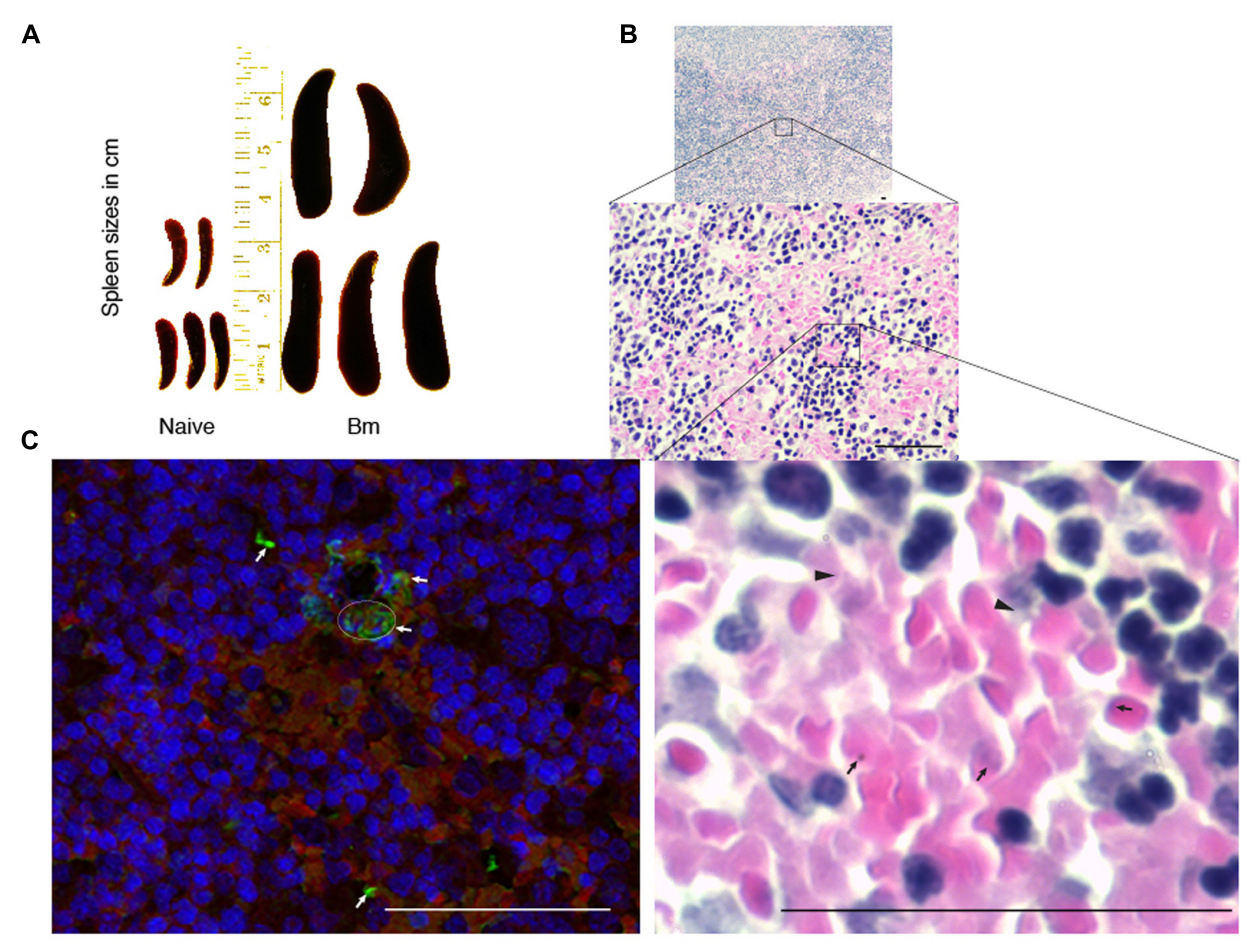

FIGURE 3 | Impact of B. microti infection on spleen of the infected mice. (A) B. microti infection resulted in a significant increase in spleen sizes of mice compared to uninfected, naïve mice. (B) White and red pulp zones were significantly enlarged while demarcation zone was not apparent in the spleen of $B$. microti infected mice. Numbers of lysed erythrocytes (marked by arrowheads) as well as various free parasitic forms (marked by arrows) were also observed in infected mouse spleen. (C) In IFA conducted the spleen section, red color indicates auto-fluorescence of RBCs, blue shows nuclear staining of cells while green fluorescence marks B. microti probed with infected human plasma followed by detection with Alexa fluor 488 conjugated secondary antibodies. Apparent lysed infected erythrocytes presence is marked by a circle. Several free, released parasitic forms were also detected (marked by arrows) among erythrocytes. Bars represent $25 \mu \mathrm{m}$.

determine changes in immune response in blood by analysis of plasmatic cytokines profile in response to B. microti infection. We examined the levels of 13 cytokine levels in plasma of B. microti infected versus uninfected mice. B. microti infection did not affect level of IL-9 in mouse plasma (data not shown). IFN- $\gamma$, TNF- $\alpha$, IL-2, IL-4, IL-6, IL-10, IL-13, IL-17F, and IL-22, showed significantly higher levels compared to naïve animals (Figure 4). Highest differences were observed for IL-2 of B. microti infected mice $(99.7 \mathrm{pg} / \mathrm{ml})$ compared to naïve animals $(80.8 \mathrm{pg} / \mathrm{ml})$ (Figure 4A). B. microti infected mice also displayed higher concentrations of TNF- $\alpha$ (95.2 pg/ml), IL-6 (119.8 pg/ml) and IL-10 $(207.1 \mathrm{pg} / \mathrm{ml})$ which were all significantly higher than the control group displaying concentrations of 81.8, 98.2, $107 \mathrm{pg} / \mathrm{ml}$, respectively (Figures 4B-D). IFN- $\gamma$, IL-4, IL-13, IL-17F, and IL-22 in $B$. microti infected mice showed concentrations of $101.9,118.9,161.3,99.7,83.7 \mathrm{pg} / \mathrm{ml}$, respectively, relative to the naïve animals that showed concentrations of $88.8,93.8,143$, 87, $66.4 \mathrm{pg} / \mathrm{ml}$, respectively (Figures 4E-I). Difference between IL-5, IL-17A, and IL-21 levels between B. microti infected and uninfected mice were not significant (Figures 4J-L). Considering cytokines have a short life, the changes in cytokine profile here could represent an ongoing low level B. microti infection in mice that could not be detected in blood smears but was detectable by qPCR. Furthermore, a declining cytokine levels are likely detected at this stage of infection such that potential higher levels of these cytokines presence during peak parasitemia to allow parasite clearance.

\section{DISCUSSION}

Babesia microti infection of humans has become very prominent in the last decade, both in North America and Europe (Hersh et al., 2014; Rizzoli et al., 2014; Knapp and Rice, 2015; Diuk-Wasser et al., 2016). In majority of immunocompetent individuals, infection remains unseen, with mild, flu-like symptoms or diminished hemoglobin levels and anemia. However, in combination with other tick-transmitted diseases such as Borrelia burgdorferi even in healthy person this parasite can intensify clinical disease and its severity (Krause et al., 1996b; Knapp and Rice, 2015). Babesiosis has tremendous consequences in the immunocompromised individuals and infants and can even be fatal (Usmani-Brown et al., 2013; Menis et al., 2015; Akoolo et al., 2017). Equally dangerous is newly identified route of transmission of $B$. microti, via blood transfusion. In these cases, immunocompetent donors are undiagnosed and remain Babesia carriers such that blood recipients who are often immunocompromized individuals can exhibit high morbidity and mortality (Herwaldt et al., 2011; Cushing and Shaz, 2012; Kitt et al., 2016). 

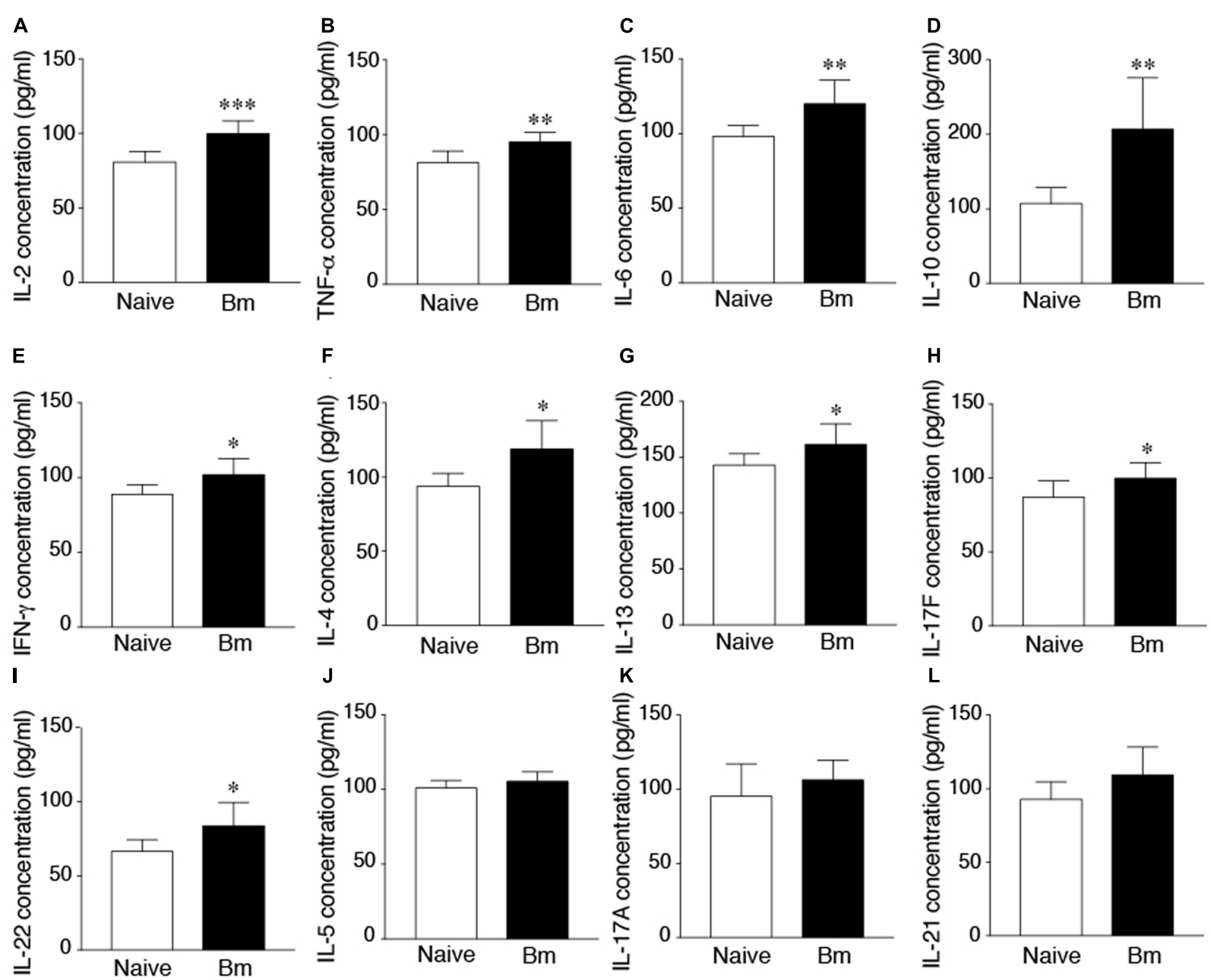

FIGURE 4 | Increased cytokine levels in mice after 21 days of infection. (A) Highest difference between B. microti infected and uninfected, naïve mice was observed in concentration of IL-2 (99.7 pg/ml compared to 80 pg/ml, $p<0.0005)$. (B-D) Concentrations of TNF- $\alpha$ (95.2 pg/ml), IL-6 (119.8 pg/ml) and IL-10 (207.1 pg/ml) were significantly higher in infected mice relative to control group $(p<0.005,<0.01,<0.01$, respectively). (E-I) IFN- $\gamma$, IL-4, IL-13, IL-17F, and IL-22 of $B$. microti infected mice, showed modest but statistically significant increase in infected mice plasma relative to the naïve animals $(p<0.05$ each; $95 \% \mathrm{Cl}$ ).

(J-L) Concentrations of IL-5, IL-17A, and IL-21 were not significantly different between infected and uninfected mice. Comparisons were made between groups using unpaired student two-tailed $t$-tests for unequal variance at 95\% Confidence Interval $(\mathrm{Cl})\left({ }^{*} p<0.05,{ }^{* *} p<0.01,{ }^{* * *} p<0.005\right)$.

Several diagnostic tests are available for diagnosis of babesiosis; however, blood smear test is still considered gold standard by CDC and WHO (Clinical and Laboratory Standards Institute, 2000; Akoolo et al., 2017). One reason is that antibodies can persist even more than a year after the clearance of Babesia infection (Vannier and Krause, 2012). On the other hand, immunocompromised or immunodeficient individuals can remain seronegative, although they could be carrier of infectious parasites, in some cases for more than 2 years (Raffalli and Wormser, 2016). PCR, as a diagnostic test for B. microti infection, was first described by Persing et al. (1992), which could detect as little as three merozoites per microliter of blood (Persing et al., 1992). Since then, method has been improved greatly. Our laboratory in 2013 developed multiplex PCR method based on molecular beacons probe for BmTPK amplicon, which significantly improved specificity and sensitivity of the assay
(Chan et al., 2013) We later also employed this test to examine human samples from endemic zone for tick-borne diseases (Akoolo et al., 2017). For majority of human samples, we were unable to determine time of the start of infection and thus, failed to determine the stage of infection in patients.

During B. microti infection, different strains of mice display majority of symptoms noticed in human patients (Vannier et al., 2004; Coleman et al., 2005; Skariah et al., 2017). Therefore, the major objective of this study was to examine if $B$. microti infection cycle in TLR4 deficient $\mathrm{C} 3 \mathrm{H} / \mathrm{HeJ}$ mice follows the same pattern and assess the impact of parasitemia on the mammalian host pathology and immune response. Our qPCR result showed very high levels of parasitic DNA in blood of mice 21 days post infection while examination of blood smears by microscopy demonstrated barely detectable parasitemia. A follow-up careful examination of slides indicated that although 
parasitized erythrocytes were not detected readily, released parasite representing various life stages of $B$. microti could be observed, thus explaining our qPCR results. These findings are similar to culture of $B$. divergens after growth synchronization by Cursino-Santos et al. (2016). In vitro culture of B. microti and B. duncani is not established yet (Skariah et al., 2017). Although we succeeded in B. microti in vitro culture for some passages when active parasites were used for infection, parasites in the absence of ring-forms in RBCs, depicting active $B$. microti, failed to infect erythrocytes. However, by reviewing blood smears in available literature, different life stages of Babesia species could be observed outside the erythrocytes (Healy and Ruebush, 1980; Shih et al., 1997; Kjemtrup and Conrad, 2000; Saito-Ito et al., 2000; Vannier et al., 2008; Sun et al., 2013). These extra-erythrocytic parasites could be mere remnants of passing parasites or exhibit still active infection. Infectivity of these parasites was not determined.

Involvement of spleen in resolution of babesiosis in humans is well established (Vannier et al., 2004; Coleman et al., 2005; Genda et al., 2016). In our experiments, spleens of all infected mice were significantly enlarged, likely due to its hyperactivity during B. microti infection because of increased hematopoietic support and macrophages activity resulting in erythrophagocytosis (Homer et al., 2000). In B. microti infected mice, various parasitic forms were distinguishable even in spleen sections stained with Hematoxilin-Eosin. Although parasitemia was undetectable by microscopy at 21 days of infection, detection of $B$. microti DNA by our qPCR supports possibility of continuing low-level infection. Our analysis of white blood cells populations in spleen at this time point showed that both CD19+ B, and CD3+ T cell populations were depleted significantly while proportion of macrophages increased. Despite subversion of splenic adaptive immune response, mice were able to clear B. microti parasitemia in blood. Supporting our results, contribution of macrophage in clearance of $B$. microti in mice has been noted previously (Terkawi et al., 2015).

To determine the existence of potentially active infection by B. microti during apparent convalescent period when certain level of immune response is maintained, we analyzed concentrations of plasmatic cytokines. We found higher concentration of IL-6, IFN- $\gamma$, and TNF- $\alpha$ that have been shown to be the major pro-inflammatory cytokines produced in response to B. microti infection (Igarashi et al., 1999; Hemmer et al., 2000b). Increased cytokines production during babesiosis in patients could be responsible for febrile illness and even myalgia. High concentrations of IL-4 and IL-10, likely produced by regulatory $B$ cells, play a major role in disease resolution but could also indicate still active B. microti infection (Hemmer et al., 2000a; Jeong et al., 2012). In fact, production of anti-inflammatory IL10 in B. microti infected mice was suggested to be important for survival of the host (Hemmer et al., 2000a). Increase in cytokines levels agree with our $\mathrm{qPCR}$ results that detected parasites in blood. Thus, inability to detect parasitemia in patients based upon infected RBCs presence appears to erroneously leave out infectious but released and free B. microti parasites. Thus, our studies follow the infection cycle of $B$. microti and provide both direct (qPCR and microscopy) and indirect (increase in the specific plasmatic cytokines) evidence of active infection in host despite apparent resolution of babesiosis as detected by parasitemia measurement.

Involvement of CD4 $\mathrm{T}$ cells, and IFN $\gamma$ cytokine has been shown to confer protective immunity against various protozoan pathogens during mammalian infection (Favre et al., 1997; Igarashi et al., 1999; Hemmer et al., 2000a; Hoft et al., 2000; Wang et al., 2004; McCall and Sauerwein, 2010). Previous studies showed that although not essential, CD4 T cells and IFN $\gamma$ also play important roles in protective immunity against B. microti infection in mice (Igarashi et al., 1999; Hemmer et al., 2000a,b; Skariah et al., 2017). Significantly high levels of IL-2, TNF $\alpha$, and IFN $\gamma$ in infected mice could be produced by activated CD4 helper (Th), primarily Th1 cells potentially in response to antigens of $B$. microti they encounter, indicating that cell mediated immunity is very important for clearance of the parasites from blood. Previously reported persistence of B. microti parasitemia in CD4-/- mice supports this hypothesis (Skariah et al., 2017). Increase in the plasmatic levels of IL-4, IL-5, and IL-13 produced by Th2 cells was not as significant. These results suggest relatively less critical role of humoral immunity in resolution of babesiosis because Th2 cells support stimulation of antibody production. Interestingly, the levels of IL-6 and IL10 cytokines, which are also produced by Th2 cells, were found to increase significantly and to a much higher levels in the infected mice. However, IL-6 and IL-10 are also produced by activated macrophage and B cells also produce IL-10 (Williams et al., 2000). High levels of IL-10 in serum of B. microti-infected mice have also been reported previously (Jeong et al., 2012). Increase of 5-10-fold levels in $\mathrm{TNF} \alpha$ production in response to human Babesia WA1 strain later in infection, suggested to be produced by CD8 $+\mathrm{T}$ cells, and concomitant decrease in IL-10 levels was occurred together with fatal disease in mice (Hemmer et al., 2000a). We observed resolution of babesiosis caused by B. microti despite significant increase in plasmatic TNF $\alpha$ level but it was not as high as reported for WA1 strain, which could be attributed to simultaneous increased production of IL-10 and its anti-inflammatory activity. IL-10 may also suppresses overexpression of both IFN $\gamma$ and $\mathrm{TNF} \alpha$ while allowing enough immune response to build that is sufficient to eradicate $B$. microt $i$ infection (Trinchieri, 2007; Couper et al., 2008a,b; Redpath et al., 2014).

Our results further emphasize the importance of macrophage in immunity against $B$. microti infection. Significant increase in IL-6 that promotes differentiation of Th17 cells (McGeachy et al., 2007) was not found to be associated with downstream increase in cytokines production by Th17 cells, a unique CD4 cells. Th17 cells produce both IL-17 and IL-21, which are implicated in various inflammatory responses (Miossec et al., 2009). Unlike previous studies with Helicobacter pylori where infection causes adenocarcinoma and produces high levels of IL17 and IL-21 (Amedei et al., 2014), only moderate increase in signature cytokines secreted by Th17 cells, such as IL-17, IL17F, IL-21, and IL-22 (Volpe et al., 2008; Korn et al., 2009), was observed in our experiments. These results suggest that Th17 cells play only a minor role during $B$. microti infection and do not trigger a pronounced inflammatory response, as observed during Babesia WA1 infection. This is not surprising because Th17 cells 
usually are found to be more important players during diverse immune-mediated diseases. In summary, our studies confirm the roles of CD4 cells and macrophage in clearance of parasitized erythrocytes during $B$. microti infection and thus, contributing to resolution of babesiosis (Igarashi et al., 1999, \#10007; Hemmer et al., 2000a,b; Aguilar-Delfin et al., 2003; Skariah et al., 2017).

\section{CONCLUSION}

Our studies with patients and mice samples indicate that qPCR could be effective for detection of both parasitized erythrocytes as well as free parasites released after lysis of infected RBCs. We confirm that spleen is important for resolution of babesiosis in mammalian hosts. Furthermore, increase in pro-inflammatory plasmatic cytokines, IL- 6 , IFN- $\gamma$, and TNF- $\alpha$ together with the presence of activated macrophage in both blood and spleen could help in resolution of infection with $B$. microti.

\section{AUTHOR CONTRIBUTIONS}

All authors contributed significantly to this work. NP conceived the study and VD and LA designed and conducted all experiment.

\section{REFERENCES}

Aguilar-Delfin, I., Homer, M. J., Wettstein, P. J., and Persing, D. H. (2001). Innate resistance to Babesia infection is influenced by genetic background and gender. Infect. Immun. 69, 7955-7958. doi: 10.1128/IAI.69.12.79557958.2001

Aguilar-Delfin, I., Wettstein, P. J., and Persing, D. H. (2003). Resistance to acute babesiosis is associated with interleukin-12- and gamma interferon-mediated responses and requires macrophages and natural killer cells. Infect. Immun. 71, 2002-2008. doi: 10.1128/IAI.71.4.2002-2008.2003

Akoolo, L., Schlachter, S., Khan, R., Alter, L., Rojtman, A. D., Gedroic, K., et al. (2017). A novel quantitative PCR detects Babesia infection in patients not identified by currently available non-nucleic acid amplification tests. BMC Microbiol. 17:16. doi: 10.1186/s12866-017-0929-2

Amedei, A., Munari, F., Bella, C. D., Niccolai, E., Benagiano, M., Bencini, L., et al. (2014). Helicobacter pylori secreted peptidyl prolyl cis, trans-isomerase drives Th17 inflammation in gastric adenocarcinoma. Intern. Emerg. Med. 9, 303-309. doi: 10.1007/s11739-012-0867-9

Borggraefe, I., Yuan, J., Telford, S. R. III, Menon, S., Hunter, R., Shah, S., et al. (2006). Babesia microti primarily invades mature erythrocytes in mice. Infect. Immun. 74, 3204-3212. doi: 10.1128/IAI.01560-05

Bose, R., Jorgensen, W. K., Dalgliesh, R. J., Friedhoff, K. T., and De Vos, A. J. (1995). Current state and future trends in the diagnosis of babesiosis. Vet. Parasitol. 57, 61-74. doi: 10.1016/0304-4017(94)03111-9

Centers for Disease Control and Prevention (2012). Babesiosis Surveillance - 18 States, 2011, ed. B. L. Herwaldt. Atlanta, GA: Centers for Disease Control and Prevention.

Chan, K., Marras, S. A., and Parveen, N. (2013). Sensitive multiplex PCR assay to differentiate Lyme spirochetes and emerging pathogens Anaplasma phagocytophilum and Babesia microti. BMC Microbiol. 13:295. doi: 10.1186/ 1471-2180-13-295

Clinical and Laboratory Standards Institute (2000). Laboratory Diagnosis of BloodBorne Parasitic Diseases, eds L. S. Gacia, S. L. Bullock-Iacullo, T. R. Fritsche, G. Kathrine, G. R. Healy, J. Palmer et al. Wayne, PA: CLSI.

Coleman, J. L., Levine, D., Thill, C., Kuhlow, C., and Benach, J. L. (2005). Babesia microti and Borrelia burgdorferi follow independent courses of infection in mice. J. Infect. Dis. 192, 1634-1641. doi: 10.1086/496891
LA started this study and VD analyzed data and wrote first draft of the manuscript. All authors have read and approved the manuscript for submission.

\section{FUNDING}

This work was supported by the National Institutes of Health (R01AI089921) and New Jersey Health Foundation grant to NP.

\section{ACKNOWLEDGMENTS}

We greatly appreciate Drs. Kristine Gedroic, MD, of the Gedroic Center and Dr. Albert Rojtman, MD, of Meridian hospitals/ Jersey Shore University Medical Center for providing us aliquots of coded patient blood samples they collected for clinical testing. We thank Donald Alderson of Rutgers University Biostatistics and Epidemiology Services Center for helping in statistical analyses of our data. We also appreciate assistance from Luke Fritzky and Joel Pierre of histology core of Rutgers Biomedical and Health Sciences in spleen preparation, sectioning and staining for histopathological examination.

Couper, K. N., Blount, D. G., and Riley, E. M. (2008a). IL-10: the master regulator of immunity to infection. J. Immunol. 180, 5771-5777.

Couper, K. N., Blount, D. G., Wilson, M. S., Hafalla, J. C., Belkaid, Y., Kamanaka, M., et al. (2008b). IL-10 from CD4CD25Foxp3CD127 adaptive regulatory $\mathrm{T}$ cells modulates parasite clearance and pathology during malaria infection. PLOS Pathog. 4:e1000004. doi: 10.1371/journal.ppat. 1000004

Cursino-Santos, J. R., Alhassan, A., Singh, M., and Lobo, C. A. (2014). Babesia: impact of cold storage on the survival and the viability of parasites in blood bags. Transfusion 54, 585-591. doi: 10.1111/trf.12357

Cursino-Santos, J. R., Singh, M., Pham, P., Rodriguez, M., and Lobo, C. A. (2016). Babesia divergens builds a complex population structure composed of specific ratios of infected cells to ensure a prompt response to changing environmental conditions. Cell. Microbiol. 18, 859-874. doi: 10.1111/cmi.12555

Cushing, M., and Shaz, B. (2012). Transfusion-transmitted babesiosis: achieving successful mitigation while balancing cost and donor loss. Transfusion 52, 1404-1407. doi: 10.1111/j.1537-2995.2012.03746.x

Diuk-Wasser, M. A., Vannier, E., and Krause, P. J. (2016). Coinfection by Ixodes tick-borne pathogens: ecological, epidemiological, and clinical consequences. Trends Parasitol. 32, 30-42. doi: 10.1016/j.pt.2015.09.008

Dunn, J. M., Krause, P. J., Davis, S., Vannier, E. G., Fitzpatrick, M. C., Rollend, L., et al. (2014). Borrelia burgdorferi promotes the establishment of Babesia microti in the northeastern United States. PLOS ONE 9:e115494. doi: 10.1371/journal. pone. 0115494

Fang, D. C., and McCullough, J. (2016). Transfusion-transmitted Babesia microti. Transfus. Med. Rev. 30, 132-138. doi: 10.1016/j.tmrv.2016.04.002

Favre, N., Ryffel, B., Bordmann, G., and Rudin, W. (1997). The course of Plasmodium chabaudi chabaudi infections in interferon-gamma receptor deficient mice. Parasite Immunol. 19, 375-383. doi: 10.1046/j.1365-3024.1997. d01-227.x

Foppa, I. M., Krause, P. J., Spielman, A., Goethert, H., Gern, L., Brand, B., et al. (2002). Entomologic and serologic evidence of zoonotic transmission of Babesia microti, eastern Switzerland. Emerg. Infect. Dis. 8, 722-726. doi: 10.3201/eid0807.010459

Fox, L. M., Wingerter, S., Ahmed, A., Arnold, A., Chou, J., Rhein, L., et al. (2006). Neonatal babesiosis: case report and review of the literature. Pediatr. Infect. Dis. J. 25, 169-173. doi: 10.1097/01.inf.0000195438.09628.b0 
Garcia, L. S. M., Bullock-Iacullo, S. L., Fritsche, T. R., Grady, K. K., Healy, G. R., Palmer, J., et al. (2000). Laboratory Diagnosis of Blood-borne Parasitic Diseases M15-A, Vol. 20. Wayne, PA: Clinical and Laboratory Standards Institute, 1-36.

Genda, J., Negron, E. A., Lotfipour, M., Balabhadra, S., Desai, D. S., Craft, D. W., et al. (2016). Severe Babesia microti infection in an immunocompetent host in Pennsylvania. J. Investig. Med. High Impact Case Rep. 4:2324709616663774. doi: $10.1177 / 2324709616663774$

Gumber, S., Nascimento, F. S., Rogers, K. A., Bishop, H. S., Rivera, H. N., Xayavong, M. V., et al. (2016). Experimental transfusion-induced Babesia microti infection: dynamics of parasitemia and immune responses in a rhesus macaque model. Transfusion 56, 1508-1519. doi: 10.1111/trf.13521

Hanafusa, Y., Onuma, M., and Kamiyama, T. (1998). Partial protection of severe combined immunodeficient mice against infection with Babesia microti by in vitro-generated CD4 ${ }^{+} \mathrm{T}$ cell clones. J. Vet. Med. Sci. 60, 401-404. doi: 10. 1292/jvms.60.401

Healy, G. R., and Ruebush, T. K. II (1980). Morphology of Babesia microti in human blood smears. Am. J. Clin. Pathol. 73, 107-109. doi: 10.1093/ajcp/73.1.107

Hemmer, R. M., Ferrick, D. A., and Conrad, P. A. (2000a). Role of T cells and cytokines in fatal and resolving experimental babesiosis: protection in TNFRp55 $5^{-/}$mice infected with the human Babesia WA1 parasite. J. Parasitol. $86,736-742$.

Hemmer, R. M., Ferrick, D. A., and Conrad, P. A. (2000b). Up-regulation of tumor necrosis factor-alpha and interferon-gamma expression in the spleen and lungs of mice infected with the human Babesia isolate WA1. Parasitol. Res. 86, 121-128.

Herman, J. H., Ayache, S., and Olkowska, D. (2010). Autoimmunity in transfusion babesiosis: a spectrum of clinical presentations. J. Clin. Apher. 25, 358-361. doi: $10.1002 /$ jca. 20262

Hersh, M. H., Ostfeld, R. S., Mchenry, D. J., Tibbetts, M., Brunner, J. L., Killilea, M. E., et al. (2014). Co-infection of blacklegged ticks with Babesia microti and Borrelia burgdorferi is higher than expected and acquired from small mammal hosts. PLOS ONE 9:e99348. doi: 10.1371/journal.pone.0099348

Herwaldt, B. L., Linden, J. V., Bosserman, E., Young, C., Olkowska, D., and Wilson, M. (2011). Transfusion-associated babesiosis in the United States: a description of cases. Ann. Intern. Med. 155, 509-519. doi: 10.7326/0003-4819155-8-201110180-00362

Hoft, D. F., Schnapp, A. R., Eickhoff, C. S., and Roodman, S. T. (2000). Involvement of $\mathrm{CD}^{+}$Th1 cells in systemic immunity protective against primary and secondary challenges with Trypanosoma cruzi. Infect. Immun. 68, 197-204. doi: 10.1128/IAI.68.1.197-204.2000

Homer, M. J., Aguilar-Delfin, I., Telford, S. R. III, Krause, P. J., and Persing, D. H. (2000). Babesiosis. Clin. Microbiol. Rev. 13, 451-469. doi: 10.1128/CMR.13.3. 451-469.2000

Hunfeld, K. P., Ernst, M., Zachary, P., Jaulhac, B., Sonneborn, H. H., and Brade, V. (2002). Development and laboratory evaluation of a new recombinant ELISA for the serodiagnosis of Lyme disease. Wien. Klin. Wochenschr. 114, 580-585.

Igarashi, I., Suzuki, R., Waki, S., Tagawa, Y.-I., Seng, S., Tum, S., et al. (1999). Roles of $\mathrm{CD}^{+} \mathrm{T}$ cells and gamma interferon in protective immunity against Babesia microti infection in mice. Infect. Immun. 67, 4143-4148.

Jahfari, S., Hofhuis, A., Fonville, M., Van Der Giessen, J., Van Pelt, W., and Sprong, H. (2016). Molecular detection of tick-borne pathogens in humans with tick bites and erythema migrans, in the Netherlands. PLOS Negl. Trop. Dis. 10:e0005042. doi: 10.1371/journal.pntd.0005042

Jeong, Y. I., Hong, S. H., Cho, S. H., Lee, W. J., and Lee, S. E. (2012). Induction of IL-10-producing $\mathrm{CD} 1 \mathrm{~d}^{\text {high }} \mathrm{CD}^{+}$regulatory B cells following Babesia microtiinfection. PLOS ONE 7:e46553. doi: 10.1371/journal.pone.0046553

Joseph, J. T., Purtill, K., Wong, S. J., Munoz, J., Teal, A., Madison-Antenucci, S., et al. (2012). Vertical transmission of Babesia microti, United States. Emerg. Infect. Dis. 18, 1318-1321. doi: 10.3201/eid1808.110988

Joseph, J. T., Roy, S. S., Shams, N., Visintainer, P., Nadelman, R. B., Hosur, S., et al. (2011). Babesiosis in lower Hudson valley, New York, USA. Emerg. Infect. Dis. 17, 843-847. doi: 10.3201/eid1705.101334

Kitt, E., Keaton, A. A., and Graf, E. H. (2016). The brief case: probable transfusiontransmitted babesiosis in a transplant recipient. J. Clin. Microbiol. 54, 26322634. doi: 10.1128/JCM.00981-16

Kjemtrup, A. M., and Conrad, P. A. (2000). Human babesiosis: an emerging tickborne disease. Int. J. Parasitol. 30, 1323-1337. doi: 10.1016/S0020-7519(00) 00137-5
Knapp, K. L., and Rice, N. A. (2015). Human coinfection with Borrelia burgdorferi and Babesia microti in the United States. J. Parasitol. Res. 2015:587131. doi: $10.1155 / 2015 / 587131$

Korn, T., Bettelli, E., Oukka, M., and Kuchroo, V. K. (2009). IL-17 and Th17 cells. Annu. Rev. Immunol. 27, 485-517. doi: 10.1146/annurev.immunol.021908. 132710

Krause, P. J., Telford, S. III, Spielman, A., Ryan, R., Magera, J., Rajan, T. V., et al. (1996a). Comparison of PCR with blood smear and inoculation of small animals for diagnosis of Babesia microti parasitemia. J. Clin. Microbiol. 34, 2791-2794.

Krause, P. J., Telford, S. R. III, Spielman, A., Sikand, V., Ryan, R., Christianson, D., et al. (1996b). Concurrent Lyme disease and babesiosis. Evidence for increased severity and duration of illness. JAMA 275, 1657-1660.

Lempereur, L., Shiels, B., Heyman, P., Moreau, E., Saegerman, C., Losson, B., et al. (2015). A retrospective serological survey on human babesiosis in Belgium. Clin. Microbiol. Infect. 21, 96.e1-96.e7. doi: 10.1016/j.cmi.2014.07.004

Lobo, C. A., Cursino-Santos, J. R., Alhassan, A., and Rodrigues, M. (2013). Babesia: an emerging infectious threat in transfusion medicine. PLOS Pathog. 9:e1003387. doi: 10.1371/journal.ppat.1003387

Luckett, R., Rodriguez, W., and Katz, D. (2014). Babesiosis in pregnancy. Obstet. Gynecol. 124, 419-422. doi: 10.1097/AOG.0000000000000222

Magnarelli, L. A., Jw, I. J., Dumler, J. S., Heimer, R., and Fikrig, E. (1998). Reactivity of human sera to different strains of granulocytic ehrlichiae in immunodiagnostic assays. J. Infect. Dis. 178, 1835-1838. doi: 10.1086/314516

Mayne, P. J. (2015). Clinical determinants of Lyme borreliosis, babesiosis, bartonellosis, anaplasmosis, and ehrlichiosis in an Australian cohort. Int. J. Gen. Med. 8, 15-26. doi: 10.2147/IJGM.S75825

McCall, M. B., and Sauerwein, R. W. (2010). Interferon-gamma-central mediator of protective immune responses against the pre-erythrocytic and blood stage of malaria. J. Leukoc. Biol. 88, 1131-1143. doi: 10.1189/jlb.0310137

McGeachy, M. J., Bak-Jensen, K. S., Chen, Y., Tato, C. M., Blumenschein, W., Mcclanahan, T., et al. (2007). TGF-beta and IL-6 drive the production of IL17 and IL-10 by $\mathrm{T}$ cells and restrain $\mathrm{T}(\mathrm{H})-17$ cell-mediated pathology. Nat. Immunol. 8, 1390-1397. doi: 10.1038/ni1539

Meeusen, E., Lloyd, S., and Soulsby, E. J. (1985). Antibody levels in adoptively immunized mice after infection with Babesia microti or injection with antigen fractions. Aust. J. Exp. Biol. Med. Sci. 63(Pt 3), 261-272. doi: 10.1038/icb.1985.29

Menis, M., Forshee, R. A., Kumar, S., Mckean, S., Warnock, R., Izurieta, H. S., et al. (2015). Babesiosis occurrence among the elderly in the United States, as recorded in large Medicare databases during 2006-2013. PLOS ONE 10:e0140332. doi: 10.1371/journal.pone.0140332

Michelet, L., Delannoy, S., Devillers, E., Umhang, G., Aspan, A., Juremalm, M., et al. (2014). High-throughput screening of tick-borne pathogens in Europe. Front. Cell. Infect. Microbiol. 4:103. doi: 10.3389/fcimb.2014.00103

Miossec, P., Korn, T., and Kuchroo, V. K. (2009). Interleukin-17 and type 17 helper T cells. N. Engl. J. Med. 361, 888-898. doi: 10.1056/NEJMra0707449

Moutailler, S., Valiente Moro, C., Vaumourin, E., Michelet, L., Tran, F. H., Devillers, E., et al. (2016). Co-infection of ticks: the rule rather than the exception. PLOS Negl. Trop. Dis. 10:e0004539. doi: 10.1371/journal.pntd. 0004539

Persing, D. H., Mathiesen, D., Marshall, W. F., Telford, S. R., Spielman, A., Thomford, J. W., et al. (1992). Detection of Babesia microti by polymerase chain reaction. J. Clin. Microbiol. 30, 2097-2103.

Raffalli, J., and Wormser, G. P. (2016). Persistence of babesiosis for $>2$ years in a patient on rituximab for rheumatoid arthritis. Diagn. Microbiol. Infect. Dis. 85, 231-232. doi: 10.1016/j.diagmicrobio.2016.02.016

Redpath, S. A., Fonseca, N. M., and Perona-Wright, G. (2014). Protection and pathology during parasite infection: IL-10 strikes the balance. Parasite Immunol. 36, 233-252. doi: 10.1111/pim.12113

Rizzoli, A., Silaghi, C., Obiegala, A., Rudolf, I., Hubalek, Z., Foldvari, G., et al. (2014). Ixodes ricinus and its transmitted pathogens in urban and peri-urban areas in Europe: new hazards and relevance for public health. Front. Public Health 2:251. doi: 10.3389/fpubh.2014.00251

Ruebush, M. J., and Hanson, W. L. (1979). Susceptibility of five strains of mice to Babesia microti of human origin. J. Parasitol. 65, 430-433. doi: 10.2307/3280290

Saito-Ito, A., Tsuji, M., Wei, Q., He, S., Matsui, T., Kohsaki, M., et al. (2000). Transfusion-acquired, autochthonous human babesiosis in Japan: isolation of Babesia microti-like parasites with hu-RBC-SCID mice. J. Clin. Microbiol. 38, 4511-4516. 
Shih, C. M., Liu, L. P., Chung, W. C., Ong, S. J., and Wang, C. C. (1997). Human babesiosis in Taiwan: asymptomatic infection with a Babesia microti-like organism in a Taiwanese woman. J. Clin. Microbiol. 35, $450-454$.

Sinski, E., Welc-Faleciak, R., and Poglod, R. (2011). Babesia spp. infections transmitted through blood transfusion. Wiad. Parazytol. 57, 77-81.

Skariah, S., Arnaboldi, P., Dattwyler, R. J., Sultan, A. A., Gaylets, C., Walwyn, O., et al. (2017). Elimination of Babesia microti is dependent on intraerythrocytic killing and CD4 ${ }^{+}$T cells. J. Immunol. 199, 633-642. doi: 10.4049/jimmunol. 1601193

Sun, J. H., Han, J. P., Feng, Z., and Hu, W. (2013). Research progress on diagnostic methods for Babesia microti infection. Zhongguo Ji Sheng Chong Xue Yu Ji Sheng Chong Bing Za Zhi 31, 235-237, 241.

Terkawi, M. A., Cao, S., Herbas, M. S., Nishimura, M., Li, Y., Moumouni, P. F., et al. (2015). Macrophages are the determinant of resistance to and outcome of nonlethal Babesia microti infection in mice. Infect. Immun. 83, 8-16. doi: 10.1128/IAI.02128-14

Trinchieri, G. (2007). Interleukin-10 production by effector T cells: Th1 cells show self control. J. Exp. Med. 204, 239-243. doi: 10.1084/jem.20070104

United States Food and Drug Administration (2014). Fatalities Reported to FDA Following Blood Collection and Transfusion. Silver Spring, MD: Food and Drug Administration.

Usmani-Brown, S., Halperin, J. J., and Krause, P. J. (2013). Neurological manifestations of human babesiosis. Handb. Clin. Neurol. 114, 199-203. doi: 10.1016/B978-0-444-53490-3.00014-5

Vannier, E., Borggraefe, I., Telford, S. R. III, Menon, S., Brauns, T., Spielman, A., et al. (2004). Age-associated decline in resistance to Babesia microti is genetically determined. J. Infect. Dis. 189, 1721-1728. doi: 10.1086/ 382965

Vannier, E., Gewurz, B. E., and Krause, P. J. (2008). Human babesiosis. Infect. Dis. Clin. North Am. 22, 469-488, viii-ix. doi: 10.1016/j.idc.2008.03.010

Vannier, E., and Krause, P. J. (2012). Human babesiosis. N. Engl. J. Med. 366, 2397-2407. doi: 10.1056/NEJMra1202018
Volpe, E., Servant, N., Zollinger, R., Bogiatzi, S. I., Hupe, P., Barillot, E., et al. (2008). A critical function for transforming growth factor-beta, interleukin 23 and proinflammatory cytokines in driving and modulating human $\mathrm{T}(\mathrm{H})-17$ responses. Nat. Immunol. 9, 650-657. doi: 10.1038/ni.1613

Wang, X., Kang, H., Kikuchi, T., and Suzuki, Y. (2004). Gamma interferon production, but not perforin-mediated cytolytic activity, of $\mathrm{T}$ cells is required for prevention of toxoplasmic encephalitis in BALB/c mice genetically resistant to the disease. Infect. Immun. 72, 4432-4438. doi: 10.1128/IAI.72.8.4432-4438. 2004

Williams, J. A., Pontzer, C. H., and Shacter, E. (2000). Regulation of macrophage interleukin-6 (IL-6) and IL-10 expression by prostaglandin E2: the role of p38 mitogen-activated protein kinase. J. Interferon Cytokine Res. 20, 291-298. doi: 10.1089/107999000312423

Wormser, G. P., Villafuerte, P., Nolan, S. M., Wang, G., Lerner, R. G., Saetre, K. L., et al. (2015). Neutropenia in congenital and adult babesiosis. Am. J. Clin. Pathol. 144, 94-96. doi: 10.1309/AJCP2PHH4HBVHZFS

Yoshinari, N. H., Abrao, M. G., Bonoldi, V. L., Soares, C. O., Madruga, C. R., Scofield, A., et al. (2003). Coexistence of antibodies to tick-borne agents of babesiosis and Lyme borreliosis in patients from Cotia county, State of Sao Paulo, Brazil. Mem. Inst. Oswaldo Cruz 98, 311-318. doi: 10.1590/S007402762003000300004

Conflict of Interest Statement: The authors declare that the research was conducted in the absence of any commercial or financial relationships that could be construed as a potential conflict of interest.

Copyright (c) 2018 Djokic, Akoolo and Parveen. This is an open-access article distributed under the terms of the Creative Commons Attribution License (CC BY). The use, distribution or reproduction in other forums is permitted, provided the original author(s) and the copyright owner are credited and that the original publication in this journal is cited, in accordance with accepted academic practice. No use, distribution or reproduction is permitted which does not comply with these terms. 